\title{
Assessment of knowledge and attitudes about responsibility of visitors to health units during a quarantine of COVID 19 in Mongolia
}

\author{
Enkh-Amgalan Byambajav ${ }^{1}$, Chimedsuren Ochir ${ }^{2}$, Myadagmaa Jaalkhorol ${ }^{3}$, \\ Khandmaa Sukhbaatar ${ }^{4}$, Oyunbileg Dulamsuren ${ }^{5}$ \\ ${ }^{1}$ Department of Finance, Business School, National University of Mongolia, Ulaanbaatar, \\ Mongolia \\ ${ }^{2}$ Graduate School, Mongolian National University of Medical Sciences, Ulaanbaatar, Mongolia \\ ${ }^{3}$ Department of Preventive Medicine, School of Public Health, Mongolian National University \\ of Medical Sciences, Ulaanbaatar, Mongolia \\ ${ }^{4}$ Department of Health Social Work and Social Sciences, School of Public Health, Mongolian \\ National University of Medical Sciences, Ulaanbaatar, Mongolia \\ ${ }^{5}$ Department of Health Social Work and Social Sciences, School of Public Health, Mongolian \\ National University of Medical Sciences, Ulaanbaatar, Mongolia \\ Corresponding Author: Oyunbileg Dulamsuren \\ E-mail: Oyunbileg.du@mnums.edu.mn
}

\begin{abstract}
Background: Only a few studies have assessed the knowledge and attitudes about responsibility of visitors to health units during COVID-19 quarantine period. This study aimed to examine the knowledge and attitudes of clients and citizens about their role during visits to health units.

Methodology: We analyzed cross-sectional data collected from 214 participants from the Bayanzurkh, Khan-Uul, and Chingeltei districts in Ulaanbaatar, Mongolia, using descriptive and multivariate logistic regression analysis methods.

Results: Of the total participants, $47.7 \%$ (102) of the respondents were men, $52.3 \%$ (112) were women, most of them were aged 20-24 (31.3\%) and 25-29 (11.7\%). The average score was 2.3, the average knowledge level was $39.35 \%$, the average score was 1.85 , and the average knowledge level was $19.9 \%$. $54.2 \%$ of respondents know, $45.8 \%$ did not know and $74.3 \%$ did not know the provisions of Article 43.2.3 of the Law on Healthcare "Prevention of the spread of infectious diseases and compliance with the quarantine regime", which is one of the main provisions that must be observed in time of COVID-19 outbreak.

Conclusion: During the outbreak of COVID-19, clients of health care organizations do not have a sufficient level of knowledge (39.3\%) about their responsibilities under the law and do not follow the rules and regulations for communicable diseases.
\end{abstract}

Keywords: COVID-19, responsibility, health care, knowledge, attitude, engagement, public health emergency, COVID-19.

\section{Introduction}

According to the World Health Organization (WHO) the worldwide outbreak COVID-19 has already spread to 223 countries, and become a serious public health problem. It is a social 
responsibility for everyone to contribute to the well-being of the community while raising human rights issues related to the pandemic [1-2].

The first case of COVID-19 infection in Mongolia was reported in March 2020, as a result of the rapid response, the infection was limited to people arriving from outside the country until November. On November 10, 2020, the first case of domestic infection was registered, and as of July 2021, 147,253 cases and 734 deaths were registered in 21 clusters in Ulaanbaatar and 20 aimags. Over the past month, an average of more than 1,000 cases have been reported per day, and the number of infections is growing rapidly [3-4].

During of the COVID-19 pandemic, health care providers must have the right to access quality health care, as well as a responsibility to protect their own and the public's health. According to the World Health Organization, governments, international agencies, health care organizations have a responsibility to provide health care to all people to the best of their ability, but this may not be possible during a pandemic where health care resources are limited. Awareness of these responsibilities is critical [5]. While the intensive spread of infection is not necessarily caused due to ignorance of Article 43.2.3 of the Law on Health of Mongolia "Prevention of the spread of infectious diseases and observance of quarantine regime" and protection from infectious diseases. The causes may be due to non-compliance with the regime imposed by the authorities, lack of personal discipline and lack of awareness of their responsibilities. ${ }^{6}$ Therefore, we determined it is important to assess the legal knowledge and attitudes of health care providers about their responsibilities during the COVID-19 pandemic.

\section{Methodology}

\section{Study design}

This study adopted a cross-sectional design and the visitor health units located in Bayanzurkh, Khan-Uul and Chingeltei districts of Ulaanbaatar. A quantitative research method was used for data collection.

\section{Study participants}

The survey was conducted at the health units located in Bayanzurkh, Khan-Uul and Chingeltei districts of Ulaanbaatar. 214 citizens served by 5 health care providers were randomly selected.

\section{Research ethics}

All participants provided their written consent before participating in the study. The study protocol was approved by the Ethics Committee of Mongolian National University of Medical Sciences (MNUMS).

\section{Statistical analyses}

All statistical analyses were performed with SPSS version 22.0. The study was designed using descriptive, regression, and and the chi-squared test was used for categorical variables. A multivariate regression model was used to assess whether the knowledge of the health law is affected by the age, sex, ethnicity, education, occupation, family, type of housing, marital status, and number of health care providers. $\mathrm{P}<0.05$ was considered statistically significant.

\section{Results}

Of the total participants 47.7 percent (102) of the respondents were men, 52.3 percent (112) were women, 87.9 percent were Khalkh, and 22.1 percent were other ethnic groups. In terms of education, 3.3 percent had primary education, 8.9 percent had incomplete secondary education, 36.9 percent had complete secondary education, 6.6 percent had specialized secondary education, and 43.2 percent had higher education. Citizens with 3 or more regular health facilities accounted for 56.1 percent of the respondents.

53.7 percent said they knew the role of a citizen in receiving medical services, and 46.3 percent said they did not know. 30.4 percent said that the Law on Health of Mongolia regulates the 
obligations of citizens to receive medical services, while 34.1 percent said that they do not know what legal documents regulate it.

63.1 percent answered that they knew the obligation to follow the internal rules and regulations of the health unit, 19.6 percent said they do not know, and 17.3 percent did not answer. 20.1 percent of respondents receive information about their civil rights and responsibilities from health care providers on TV, the Internet, Facebook, and friends, while 1.45 percent obtain information from newspapers and health information boards.

54.2 percent of respondents indicated they knew of Article 43.2.3 of the Law on Health; "prevention of the spread of infectious diseases and adherence to quarantine" while 45.8 percent indicated they did not know. However, 74.3 percent did not know the specific provisions of Article 43.2.3 of the Law on Health "Prevention of the spread of infectious diseases and adherence to quarantine" which is one of the essential provisions to be followed during an outbreak of COVID19 infection. 20.6 percent indicated they knew while 5.1 percent indicated they did not know that they have a duty to provide accurate and complete information about their own and their caregivers' physical health to medical professionals.

65 percent knew, 28.5 percent did not know, and 6.5 percent did not respond to the need to inform and explain to the relevant medical professionals if there were any difficulties in strictly following the treatment instructions and regimen.

Assessing the participants' knowledge of their civic responsibilities under the Health Law, 6.1 percent, 71.1 percent, and 13.1 percent did not know the 9 responsibilities of the law. The average score was 2.3 percent and the average level of knowledge was 39.3 percent. was. During the COVID-19 infection, citizens have a legal obligation to protect and prevent their own and their families' health. COVID-19 is a preventable disease, and it is possible to prevent infection if people follow simple routines such as avoiding crowded places, keeping a safe distance from people, wearing masks, and washing your hands regularly. 79.4 percent of the respondents said that they knew that they have a duty to protect and promote their own and their family's health according to the law. However, 42.5 percent did not receive a health check-up, 32.7 percent only did it once, and 14 percent did it twice, from our survey sample more than women have never had a medical inspection. (Table 1)

Table 1. Preventive medical examination in accordance with legal obligations (by gender)

\begin{tabular}{|l|c|c|c|c|c|c|c|}
\hline \multirow{2}{*}{$\begin{array}{l}\text { Number of preventive } \\
\text { examinations }\end{array}$} & \multicolumn{2}{|c|}{ Male } & \multicolumn{2}{c|}{ Female } & \multicolumn{2}{|c|}{ Total } & \multirow{2}{*}{ P value } \\
\cline { 1 - 8 } & $\mathbf{n}$ & $\mathbf{\%}$ & $\mathbf{n}$ & $\mathbf{\%}$ & $\mathbf{n}$ & $\mathbf{\%}$ & \\
\hline Never & 39 & 38.2 & 52 & 46.4 & 91 & 42.5 & \multirow{2}{*}{0.291} \\
\hline 1 time & 39 & 38.2 & 31 & 27.7 & 70 & 32.7 & \\
\hline 2 time & 14 & 13.7 & 16 & 14.3 & 30 & 14 \\
\hline 3 time & 6 & 5.9 & 9 & 8 & 15 & 7 \\
\hline 4 time & 4 & 3.9 & 4 & 3.6 & 8 & 3.7 & \\
\hline
\end{tabular}

Multivariate regression model was used to assess whether the age, sex, ethnicity, education, occupation, occupation, family, type of housing, marital status, and number of health care providers affected the knowledge of health law.

$$
y_{i}=\beta_{0}+\beta_{1} x_{1 i}+\beta_{2} x_{2 i}+\cdots+\beta_{k} x_{k i}+e_{i} \quad i=1, n
$$

$y_{i}$ is the knowledge of the model dependent variable or health law, $\beta_{i}$ is the parameters of the model, $\mathrm{x}_{\mathrm{ji}}$ is the explanatory variable or independent variables, and $\mathrm{e}_{\mathrm{i}}$ is the expression of the model error.

The analysis of the multivariate regression model was divided into 5 age groups: total sample, under 25 years old, 25 to 40 years old, 40 to 60 years old, and over 60 years old. In order to test the reliability of each model, the heteroskedastic criteria were considered to be heteroskedastic, or the variances of the error expressions were equal, and the Ramsey RESET test concluded that the model was correct and there were no missing variables. 
In addition, if the variables are interrelated, regardless of the design optimization, the accuracy of the model evaluation will be lost and the statistical significance of the coefficients will be affected. Therefore, the correlation between the independent variables was examined to see if there was a relationship between the multicollinear or independent variables.(Table 2)

The analysis of the multi-variate regression model was divided into 5 age groups: total sample, under 25 years old, 25 to 40 years old, 40 to 60 years old, and over 60 years old. The results show that the weak interrelationships between the variables do not raise the issue of multi-collinearity in model evaluation. (Table 2)

Table 2. Correlation matrix of independent variables

\begin{tabular}{|l|c|c|c|c|c|c|c|c|c|c|}
\hline \multicolumn{1}{|c|}{ Indicators } & Age & $\begin{array}{c}\text { Housing } \\
\text { type }\end{array}$ & $\begin{array}{c}\text { Education } \\
\text { level }\end{array}$ & $\begin{array}{c}\text { Number } \\
\text { of } \\
\text { families }\end{array}$ & $\begin{array}{c}\text { Number of } \\
\text { visits to } \\
\text { health } \\
\text { facilities }\end{array}$ & Employment & $\begin{array}{c}\text { Marital } \\
\text { status }\end{array}$ & Ethnicity & Profession & Gender \\
\hline Age & 1.00 & -0.07 & 0.04 & -0.10 & 0.37 & -0.05 & -0.33 & -0.06 & -0.07 & 0.03 \\
\hline Housing type & -0.07 & 1.00 & 0.18 & -0.07 & 0.02 & -0.18 & -0.06 & -0.05 & 0.03 & 0.10 \\
\hline Education level & 0.04 & 0.18 & 1.00 & -0.05 & 0.06 & -0.29 & -0.10 & 0.08 & -0.07 & -0.04 \\
\hline $\begin{array}{l}\text { Number of } \\
\text { families }\end{array}$ & -0.10 & -0.07 & -0.05 & 1.00 & -0.10 & 0.03 & 0.04 & -0.08 & 0.14 & -0.11 \\
\hline $\begin{array}{l}\text { Number of visits } \\
\text { to health } \\
\text { facilities }\end{array}$ & 0.37 & 0.02 & 0.06 & -0.10 & 1.00 & -0.05 & -0.07 & 0.02 & -0.16 & -0.04 \\
\hline Employment & -0.05 & -0.18 & -0.29 & 0.03 & -0.05 & 1.00 & 0.06 & -0.06 & 0.25 & -0.08 \\
\hline Marital status & -0.33 & -0.06 & -0.10 & 0.04 & -0.07 & 0.06 & 1.00 & -0.05 & 0.04 & -0.03 \\
\hline Ethnicity & -0.06 & -0.05 & 0.08 & -0.08 & 0.02 & -0.06 & -0.05 & 1.00 & -0.10 & 0.01 \\
\hline Profession & -0.07 & 0.03 & -0.07 & 0.14 & -0.16 & 0.25 & 0.04 & -0.10 & 1.00 & 0.03 \\
\hline Gender & 0.03 & 0.10 & -0.04 & -0.11 & -0.04 & -0.08 & -0.03 & 0.01 & 0.03 & 1.00 \\
\hline
\end{tabular}

When the sample, which included a total of 214 people, was evaluated, the coefficient of determination of the model was 0.07 , indicating that the evaluation of the model was not good. In terms of parameters, all indicators except education were not statistically significant, and education was statistically significant at the 1 percent level. In other words, the higher the level of education of the respondents, the higher their knowledge of the health law.

For the second model, young people under the age of 25, in addition to their level of education, ethnicity is important, and statistically significant at 1 percent. The negative sign indicates that the higher the non-Khalkh ethnicity, the lower the knowledge of the law on health care. A value of the coefficient of determination of 0.17 indicates poor model representation.

The third model, for young people aged 25 to 40 , has a coefficient of determination of 0.36 , indicating improved representation compared to the previous two models. Also, the largest number of variables considered in the model was statistically significant. Good housing conditions, a high level of education, frequent hospitalizations, and the type of work they do have a positive effect on their legal knowledge.

For the fourth model, the 40 - to 60 -year-olds, the coefficient of determination is reduced and the model's representation is impaired. It also appears that better housing conditions and occupations have a negative impact on the design, or that better housing conditions and better legal knowledge are less important.

For the fifth model, over the age of 60 , although the values of the coefficients of determination of the model were better than in the previous models, none of the parameters were statistically significant. In other words, the factors considered in this model have no effect on the knowledge of civic responsibilities set out in the health law. The main conclusion to be drawn from this is that there are no factors related to improving legal knowledge for retirees. Ethnicity was excluded from the model evaluation. The main reason for this is that everyone in this group indicated they were of Khalkh ethnicity. 
Taken together, the five models show that factors such as age, family size, marital status, occupation, and gender have no effect on health law knowledge. (Table 3)

Table 3. Results of the evaluation of the regression model of civic awareness

\begin{tabular}{|c|c|c|c|c|c|}
\hline Indicators & Total & $<25$ & $25=<x<40$ & $40<=x<60$ & $60<$ \\
\hline $\mathrm{C}$ & 0.59 & 1.49 & -2.14 & 5.43 & -4.58 \\
\hline Age & 0.00 & -0.02 & -0.04 & -0.05 & 0.16 \\
\hline Housing type & 0.06 & 0.20 & $0.33 * * *$ & $-0.37 *$ & 1.46 \\
\hline Education & $0.50^{* * *}$ & $0.68^{* *}$ & $0.60^{\star *}$ & 0.02 & 1.20 \\
\hline $\begin{array}{l}\text { Number of } \\
\text { families }\end{array}$ & 0.03 & -0.11 & 0.06 & 0.20 & -0.68 \\
\hline $\begin{array}{l}\text { Number of visits } \\
\text { to health facilities }\end{array}$ & 0.01 & -0.29 & $0.53^{* *}$ & -0.09 & -0.26 \\
\hline Employment & 0.04 & 0.03 & $0.32^{* *}$ & $-0.33^{* *}$ & -1.77 \\
\hline Marital status & 0.27 & 0.41 & 0.00 & 0.60 & -0.69 \\
\hline Ethnicity & -0.10 & $-0.44^{* * *}$ & 0.24 & 0.32 & - \\
\hline Profession & 0.04 & 0.03 & 0.07 & 0.19 & -0.41 \\
\hline Gender & 0.39 & 0.17 & 0.05 & 0.61 & -0.40 \\
\hline R2 & 0.07 & 0.17 & 0.36 & 0.24 & 0.38 \\
\hline Sample size & 214 & 86 & 60 & 55 & 13 \\
\hline
\end{tabular}

Note: ${ }^{* * *} 1$ percent statistically significant, ${ }^{* *} 5$ percent statistically significant, ${ }^{*} 10$ percent statistically significant, Dependent variables: Knowledge of civic responsibilities set out in the Health Law

We examined the attitudes of the survey participants on how they fulfill their civic responsibilities when receiving medical care. Of all the participants, 68.7 percent of the respondents did not inform us about the responsibilities of medical professionals when providing services to clients, 65.4 percent did not fulfill their responsibilities and 51.4 percent did not follow the internal rules and regulations of health organizations. However, 65.4 percent of the respondents believe that it is important to respect the rights of others when receiving medical care during this epidemic, and 69.6 percent believe that citizens should be aware of their role in improving health care.

\section{Discussion}

The present study found that during the outbreak of COVID-19, clients of health care organizations do not have a sufficient level of knowledge (39.3\%) about their responsibilities under the law and do not follow the rules and regulations for communicable diseases. Knowledge levels varied dependent on the age, level of education, living conditions, ethnicity and occupation of the citizens. This COVID-19 study aimed to assess the level of knowledge and attitudes of citizens receiving health care during the pandemic, as defined in the Mongolian Health Law.

To our knowledge, the present study is the first to determine the level of knowledge and attitudes of citizens about their role in communicable diseases during the COVID-19 epidemic in Mongolia. There would also appear to be to inadequate research into this issue in other countries although it is recognized that knowledge and attitudes will vary across different countries dependent on the specific conditions that exist in each country.

One of the issues that must be addressed during the COVID-19 pandemic is the adherence to infection control regimes and the implementation of laws, rules and recommendations aimed at preventing and reducing communicable diseases, recognizing that the rights of one person to another are limited within the social framework of the country. On the other hand, citizens should be aware of their legal responsibilities, implement them, and act responsibly, and understand that working with health organizations to protect their health can stop the chain of infection and reduce its spread [6-9]. 
Furthermore, the WHO recommends that in order to reduce the spread of the COVID-19 pandemic, citizens should have the health knowledge to perform simple actions such as washing their hands, wearing masks, and keeping a safe distance from other people, and be responsible for adhering to socially responsible standards [10]. Health education and civic awareness are affected by our level of education [4] with 12.5 percent of those with primary education unaware of their civic responsibilities, and 87.5 percent were unaware of one of their civic responsibilities under the health law, consistent with Leena Paakkari's et al [11].

On the other hand, ethics and accountability are important in respecting vulnerable groups in assessing the policies and risks of government and health care in order to reduce and stop the epidemic. This is due to the fact that vulnerable citizens' lack of ethical responsibility reduces risk [12]. In our study, as is important for young people under 25 to have an ethnic background in addition to their level of education.

Knowledge of civic responsibilities was positively influenced by the number of visits to the hospital and the type of employment, and the better the housing conditions for those aged 40-60, the better the legal knowledge of their civic duties. However, there were no factors related to improving legal knowledge for retirees. The influence of age and education and employment on knowledge levels was consistent with the findings of Sulistyawati Sulistyawati and Bates and others [13-14]. This is due to the fact that awareness of the role of citizens in the event of a pandemic varies with age, and the ability of citizens to act in terms of organization, unity and common interests is consistent to the survey conducted in Chile [15-16].

Our survey found that the level of knowledge of citizens about their civic responsibilities under the law is 39.3 percent, which means that they do not fulfill their responsibilities to live a healthy life, receive health education, prevent disease, and promote mental health, especially during quarantine. This result is consistent with Md Mahbub Hossain's et al survey [17]. Therefore, in order to increase the level of knowledge on civic responsibilities set forth in the health law, it is important to educate non-Khalkh ethnic youth about legal issues in terms of education, living conditions, occupation and youth. It is important to coordinate and implement educational training and advocacy activities, as this demonstrates the importance of knowledge. Increasing access to information and intensifying health education in the health sector is important for the prevention of COVID-19 pandemic and the improvement of knowledge and skills about civic responsibilities [18].

According to Bester and others, proper social organization and individual responsibility during a pandemic are critical to a country's security. The results of our study show that the responsibility of citizens is important to protect the well-being of society from the effects of the plague and to improve effective response levels to the epidemic [19]. Furthermore, French Bourgeois and others [20] found that the role of civics and social norms in adhering to public health recommendations for COVID-19 infection. It has been established that civic duty is important to follow health advice and to understand one's responsibilities. While 77 percent of Canadians follow public health guidelines, 54.2 percent in our survey do not. This proves the importance of training and educating citizens in terms of their social responsibilities.

One cross-sectional study reported on some of the important ethical questions that arise in the context of the coronavirus epidemic and highlighted the need for governments to build trust and solidarity with its citizens [21]. In our study, civic awareness and knowledge of personal social responsibilities was poor and has resulted in the rapid spread of COVID-19 infection levels.

Also, according to Gostin Lawrence $\mathrm{O}$ et al, without human rights education, human rights becomes a public health issue. This survey emphasized that accountability was more important than human rights in an unprecedented epidemic [22].

An Ethiopian cross-sectional study showed that a lack of education in multi-factor logistic regression analysis and a lack of information sources contribute to poor client prevention practices for COVID-19 infection, and correlation analysis has shown a positive correlation between knowledge and practice $[17,23]$. In the regression analysis, citizens' knowledge and skills depended on education, living environment, occupation [14,25], and ethnicity (minority), which was similar to the results of a survey in Nepal [24]. Meanwhile, in our study, the level of knowledge of citizens over the age of 60 had no effect on their civic responsibilities, and the level of knowledge of 
uneducated people was inadequate, which is consistent with the study of Emily Ying Yang Chan and others [26].

In order to reduce the spread of COVID-19, it is very important to know, observe and be responsible for the civic duties set forth in the laws, rules and regulations of the legal framework.

During the COVID-19 infection, visitors to health facilities have a low level of knowledge about their legal responsibilities, unsatisfactory compliance with communicable disease regulations, and a lack of awareness of their responsibilities. This has led to an increase in the spread of the COVID19 infection. Therefore, it is necessary to organize trainings and advertisements aimed at reducing the spread of COVID-19 pandemic, taking into account the age, ethnicity, education, living conditions and occupation of citizens, and to promote laws and regulations on the rights and responsibilities of citizens during periods of communicable diseases like COVID-19.

\section{REFERENCES}

1. Berger ZD, Evans NG, Phelan AL, Silverman RD. COVID 19: control measures must be equitable and inclusive. BMJ 2020;368:1141.

2. Rizal A, Hariandy Hamid A. Social responsibility of medical journal: a concern for COVID 19 pandemic. Medical Journal of Indonesia 2020;29:1-3.

3. COVID 19 situation information. Ulaanbaatar: Mongolia, Ministry of Health. Available from: https:// https://covid19.mohs.mn/p/cat/post/57/?page=78 [cited 2020 Nov 11].

4. COVID 19 situation information. Ulaanbaatar: Mongolia, Ministry of Health. Available from: https:// https://covid19.mohs.mn/p/cat/post/57/?page=6 [cited 2021 March 31].

5. COVID-19: Ethics, resource allocation and priority setting. World Health Organization. Available from: https://www.who.int/emergencies/diseases/novel-coronavirus-2019/question-andanswers-hub/coronavirus-disease-COVID-19-ethics-resource-allocation-and-priority-setting [cited 2020 April 20].

6. Health law. Mongolia. Available from: https://www.legalinfo.mn/law/details/49 [cited 2020 September 27].

7. The constitution of Mongolia. Available from: https://www.legalinfo.mn/law/details/367 [cited 2020 September 27].

8. COVID-19 Plague Control law. Mongolia. Available from: https://www.legalinfo.mn/law/details/15312?lawid=15312 [cited 2020 September 27].

9. Ministry of Health. Order No. 406 of the Minister of Health of 2019. Code of Ethics for Medical Professionals. Code of ethics for health care clients.

10. John Zarocostas. How to fight an infodemic. World report. Vol 395. 2020 Feb 29. www.thelancet.com

11. Leena Paakkari, Orkan Okan. COVID 19: health literacy is an underestimated problem. The Lancet Public Health 2020;5:249-50.

12. Sulistyawati Sulistyawati, Rokhmayanti Rokhmayanti, Budi Aji, Siwi Pramatama Mars Wijayanti, Siti Kurnia Widi Hastuti, Tri Wahyuni Sukesi, Surahma Asti Mulasari. Knowledge, Attitudes, Practices and Information Needs During the COVID 19 Pandemic in Indonesia. Risk Management and Healthcare Policy 2021;14:163-75.

13. Bates BR, Moncayo AL, Costales JA, Herrera-Cespedes CA, Grijalva MJ. Knowledge, Attitudes, and Practices towards COVID 19 among Ecuadorians during the Outbreak: An Online CrossSectional Survey. J. Community Health 2020;45:1158-67.

14. Epidemic trends, public health response and health system capacity: the Chilean experience in four months of the COVID-19 pandemic. Pub Med 2020;44:99.

15. Osvaldo A. COVID-19: Lessons for Chile. Int J Integr Care 2020;20(3):4.

16. Md Mahbub Hossain, Abida Sultana, Neetu Purohit, Mental health outcomes of quarantine and isolation for infection prevention: a systematic umbrella review of the global evidence. Epidemiol Health 2020;(42):11.

17. Taye GM, Bose L, Beressa TB, Tefera GM, Mosisa B, Dinsa H, Birhanu A,Umeta G. COVID 19 Knowledge, Attitudes, and Prevention Practices Among People with Hypertension and Diabetes Mellitus Attending Public Health Facilities in Ambo, Ethiopia. Infection and Drug Resistance 2020;13:4203-14

18. Bester JC. Justice, Well-Being, and Civic Duty in the Age of a Pandemic: Why we all Need to Do our bit. J Bioeth Inq 2020;17(4):737-42.

19. French Bourgeois L, Harell A, Stephenson L. To Follow or Not to Follow: Social Norms and Civic 
Duty during a Pandemic. Canadian J Political Sci 2020;53;(2):273-8.

20. Fahlquist JN. The moral responsibility of governments and individuals in the context of the coronavirus pandemic. Scand J Pub Health 2021;1:1-6.

21. Gostin LO, Daniely T, Huffstetler HE, Williams CR, Meier BM. The Shibboleth of Human Rights in Public Health. Lancet Public Health 2020;(9):471-2.

22. Akalu Y, Ayelign B, Molla MD. Knowledge, attitude and practice towards COVID-19 among chronic disease patients at Addis Zemen Hospital, Northwest Ethiopia. Infect Drug Resist 2020;13:1949-60.

23. Devkota HR, Sijali TR, Bogati R, Clarke A, Adhikary P, Karkee R. How Does Public Knowledge, Attitudes, and Behaviors Correlate in Relation to COVID 19? A Community-Based Cross-Sectional Study in Nepal. Front Public Health, 2021 Jan 14.

24. Banik R, Rahman M, Sikder T, Rahman QM, Mamun Ur Rashid Pranta. Knowledge, attitudes, and practices related to the COVID-19 pandemic among Bangladeshi youth: a web-based crosssectional analysis. Journal of Public Health: From Theory to Practice.

25. Emily Ying Yang Chan, Zhe Huang, Eugene Siu Kai Lo, Kevin Kei Ching Hung, Eliza Lai Yi Wong, Samuel Yeung Shan Wong. Sociodemographic Predictors of Health Risk Perception, Attitude and Behavior Practices Associated with Health-Emergency Disaster Risk Management for Biological Hazards: The Case of COVID-19 Pandemic in Hong Kong, SAR China. Int. J. Environ. Res. Public Health 2020;17:3869

Acknowledgements: Nil

Conflict of interest: Nil

Funding: Nil 